\title{
ARTIGO
}

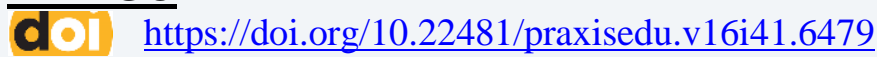

\section{POLÍTICAS E PRÁTICAS SOCIAIS NO ESTADO DA PARAÍBA APLICADAS AO \\ PROCESSO FORMATIVO DO TRABALHADOR DA EJA}

\author{
SOCIAL POLICIES AND PRACTICES IN THE STATE OF PARAÍBA APPLIED TO THE \\ FORMATION PROCESS OF EJA WORKERS
}

\author{
POLÍTICAS Y PRÁCTICAS SOCIALES EN EL ESTADO DE PARAÍBA EN EL \\ PROCESO DE FORMACIÓN DE TRABAJADORES DE EJA
}

\author{
Eloíde Teles Silva Grisi \\ Universidade Federal da Paraíba - Brasil \\ Maria das Graças Gonçalves Vieira Guerra \\ Universidade Federal da Paraíba - Brasil \\ Joseval dos Reis Miranda \\ Universidade Federal da Paraíba - Brasil
}

\begin{abstract}
Resumo: A presente pesquisa tem como objetivo analisar o processo formativo de trabalhadores e trabalhadoras da Educação de Jovens e Adultos (EJA), com vistas a políticas e práticas sociais no estado da Paraíba que envolvam essa modalidade educacional. A pesquisa procurou identificar os aspectos positivos e/ou negativos apresentados pelos estudantes da EJA e identificar o perfil desses alunos(as), em uma instituição de ensino no estado da Paraíba. A pesquisa, de caráter qualitativo, foi realizada através do método de grupo focal e a técnica do Discurso do Sujeito Coletivo-DSC foi adotada na análise dos resultados. Ao analisar as falas dos participantes e os documentos estudados, com foco no estado da Paraíba, percebeu-se fatores relevantes para os aspectos positivos e negativos de políticas e práticas sociais. Os resultados da pesquisa foram importantes para o contexto atual, pois, mesmo nas falas positivas e conformistas, prevaleceram gritos de socorro em prol de uma sociedade mais justa, que ofereça condições básicas e acessos à Educação para todos, conforme direito garantido por lei.
\end{abstract}

Palavras chave: Educação de Jovens e Adultos; Trabalhador da EJA; Políticas Educacionais da EJA.

\begin{abstract}
The aim of the present research is to analyze the training process of young and adult education workers (EJA), with emphasis on social policies and practices that concern this educational modality in the state of Paraíba. The research sought to identify the positive and / or negative aspects presented by EJA students, as well as the profile of students, in an educational institution in the state of Paraíba. The research followed the qualitative approach and was carried out based on the focus group method; and the Collective Subject Discourse-DSC technique was used for result analysis. By analyzing participants' speeches and the assessed documents, with emphasis on the state of Paraíba, it was possible perceiving the factors relevant for the positive and negative aspects of social policies and
\end{abstract}


practices. Results in the current research have shown important information for the current context, because despite the positive and conformist speeches, calls for help and for a more just society prevailed, which should provide basic conditions and access to Education for all, according to the right guaranteed by law.

Keywords: Youth and Adult Education; EJA worker; EJA Educational Policies.

Resumen: Esta investigación tiene como objetivo analizar el proceso de capacitación de los trabajadores de educación de jóvenes y adultos (EJA), el cual incluye las políticas y prácticas sociales en el estado de Paraíba. La investigación buscó identificar los aspectos positivos y / o negativos presentados por los estudiantes de EJA, e identificar el perfil de estos, en una institución educativa en el estado de Paraíba. La investigación, con características cualitativas, se llevó a cabo con el método del grupo focal y para el análisis de los resultados, se utilizó la técnica de Discurso colectivo del sujeto-DSC. Analizando los discursos de los participantes concomitantes y los documentos estudiados, con un enfoque en el estado de Paraíba, se percibieron factores relevantes para las políticas y prácticas sociales en aspectos positivos y negativos. Los resultados de la investigación mostraron ser importantes en el contexto actual porque, incluso, en los discursos positivos y conformistas, prevalecen los pedidos de ayuda a favor de una sociedad más justa, con condiciones básicas y acceso a la educación para todos, de acuerdo con el derecho garantizado por la ley.

Palabras clave: Educación de jóvenes y adultos; Trabajador de EJA; Políticas educativas de EJA.

\section{Introdução}

O Brasil está passando por sérias mudanças na educação, principalmente no âmbito curricular, em um período marcado por mudanças políticas, econômicas e sociais. Em meio a tais mudanças, em pleno século XXI, questões educacionais evidenciam-se por aspectos negativos quando a pauta é analfabetismo, no Brasil. Dados apresentados pelo Instituto Nacional de Geografia e Estatística (IBGE) comprovaram que o país encontra-se entre os dez países com maior número de adultos analfabetos do mundo, fato esse responsável por, aproximadamente, 11,3 milhões de pessoas nessa condição (IBGE, 2018) ${ }^{1}$.

O alto índice de evasão escolar na Educação de Jovens e Adultos apresentado pela pesquisa IBGE (2018), está frequentemente relacionado à falta de investimento nessa modalidade educacional e à precárias condições de vida. De acordo com análises estatísticas, essas pessoas residentes, normalmente, em comunidades carentes as quais apresentam alto índice de periculosidade. Nesse sentido, a escola precisa adequar-se para receber esse público e, assim, conseguir transformar sua condição. Com base nesse contexto, Freire (1991) afirma que:

\footnotetext{
1 A pesquisa apresentou dados estatísticos referentes ao analfabetismo de adultos no Brasil. Para maiores detalhes consultar o site https://educa.ibge.gov.br/jovens/conheca-o-brasil/populacao/18317-educacao.html
} 
A escola como um espaço de ensino-aprendizagem será então um centro de debates de ideias, soluções, reflexões, onde a organização popular vai sistematizando sua própria experiência. O filho do trabalhador deve encontrar nessa escola os meios de auto emancipação intelectual independentemente dos valores da classe dominante. A escola não é só um espaço físico. É um clima de trabalho, uma postura, um modo de ser. (FREIRE, 1991, p. 16).

Ao observar os contextos vividos por pessoas que tiveram sua alfabetização interrompida, impossibilitada, ou mesmo, anulada, em tempo pré-estabelecido pelo Plano Nacional de Educação (PNE) 2014-2024, podemos perceber a influência do êxodo rural nesse índice (IBGE, 2018). A Educação de Jovens e Adultos encontra-se amparada pela LDBEN (Lei de Diretrizes e Bases da Educação Nacional) n 9.394/96 (BRASIL, 1996) e visa incluir pessoas as quais, por algum motivo, não tiveram acesso ao ensino regular na idade apropriada.

A Pesquisa Nacional por Amostra de Domicílios Contínua (2018), realizada pelo IBGE, considerou que pessoas com 15 anos ou mais pertencem a um grupo etário que já deveria ter concluído o ensino básico, em modalidade regular. De acordo com a pesquisa, houve uma redução discreta no índice de analfabetismo - aproximadamente, 7\% - em comparação à pesquisa de 2017 (IBGE, 2018). Porém, é fator relevante e muito preocupante observar que o nordeste brasileiro apresenta o maior índice de analfabetismo do país.

Essa mesma pesquisa apresenta a Paraíba como o quarto estado brasileiro no ranking de maior índice de analfabetismo: de 16,1\%; o estado fica atrás dos estados do Maranhão (16,3\%), do Piauí (16,6\%) e de Alagoas (17,2\%), conforme os dados do IBGE (2018). É importante ressaltar que pessoas de 15 anos ou mais que estejam aptas a escrever um bilhete simples, são consideradas alfabetizadas.

Os números evidenciam um contexto aquém de uma sociedade igualitária, na qual os direitos de todos(as) aparecem enfraquecidos diante de sistemas falhos oriundos de práticas sociais direcionadas por políticas públicas. Há diferentes vieses educacionais proclamados, nas últimas décadas, pelo próprio MEC (Ministério da Educação), os quais flutuam entre desacordos e propostas que dissociam o objetivo principal da EJA, a saber: "preparar de forma consciente para entender o funcionamento do sistema sócio-político-econômico que estrutura este país que é de todos e todas (BRASIL, 2009)".

Dessa forma, a presente pesquisa de caráter qualitativo, teve o intuito de identificar o perfil de trabalhadores (as) e estudantes da Educação de Jovens e Adultos, em uma instituição de ensino da Paraíba; assim como procurou descrever as políticas públicas e práticas sociais vinculadas ao processo formativo desses indivíduos e as diretrizes educacionais voltadas à 
EJA na Paraíba. Tal procedimento foi adotado com o propósito de investigar as ações governamentais em curso, ou não, relativas a essa modalidade de ensino.

\section{Metodologia}

Ao analisar as políticas e práticas sociais identificadas como positivas ou negativas por estudantes da EJA, os quais atuam na sociedade como trabalhadores(as), a presente investigação permite o estabelecimento de diálogos com os envolvidos no contexto aqui endereçado, a fim de fomentar contribuições positivas à sociedade no que toca essa modalidade de ensino, assim como ações governamentais voltadas para esse público.

Flick (2009) contribui para a coleta de dados ao dizer que, ao se delinear o processo da pesquisa qualitativa, percebe-se que etapas isoladas se encontram muito mais ligadas umas às outras do que no processo passo-a-passo de uma pesquisa quantitativa. Assim, optamos por utilizar a técnica de grupo focal, a qual "pressupõe a existência de um foco, ou tema, em torno do qual as pessoas irão expor suas ideias, percepções, sentimentos" (GUI, 2003). O número de participantes não é consensual na literatura, porém, em média, grupos de 5 a 15 pessoas são utilizados nesse tipo de investigação.

A técnica do Discurso do Sujeito Coletivo-DSC (LEFEVRE; LEFEVRE, 2000) foi utilizada na pesquisa qualitativa para análise de resultados. Os depoimentos são a matériaprima desse método, que consiste em selecionar expressões-chave, em respostas individuais dadas a cada questão proposta. Expressões que correspondam às ideias centrais são alvos de discursos-síntese, escritos em primeira pessoa do singular; entre eles, observa-se o DSC, no qual o pensamento de um grupo ou coletividade é identificado como discurso individual.

Utilizamos três procedimentos para coleta de dados, a saber: grupo focal com os/as estudantes trabalhadores/as da EJA, em uma instituição de ensino da Paraíba. Foi realizada uma pesquisa documental de políticas públicas e práticas sociais focadas no processo formativo do/a estudante trabalhador/a que depende da EJA e nos estudos acerca das diretrizes educacionais voltadas à EJA nesse estado.

A pesquisa percorreu o caminho da criticidade, dados os desafios enfrentados por estudantes trabalhadores/as da EJA, e as políticas e práticas sociais observadas no processo formativo dessa modalidade. O estudo foi realizado no núcleo da EJA na Universidade Federal da Paraíba (UFPB), João Pessoa-PB, no Centro de Educação (CE). O local foi escolhido por ser procurado por pessoas advindas de outras cidades da Paraíba. 
Trabalhadores/as matriculados/as na EJA do CE da UFPB, no município de João Pessoa/PB, com residência atual nesse estado, participaram da pesquisa. A amostra contemplou 25 alunos/as presentes no momento da pesquisa no núcleo da EJA; os quais estão em séries correspondentes ao Ensino Médio - 20\% dos alunos matriculados nesse núcleo, nessa modalidade de ensino, foram considerados na pesquisa. Esses participantes, no período do estudo, possuíam idade superior a 18 anos e estavam devidamente matriculados no ciclo correspondente ao Ensino Médio de 2019.

Vale ressaltar ainda que todos assinaram o TCLE (Termo de Consentimento e Livre Esclarecimento) e que o presente estudo obedeceu às normas e diretrizes regulamentadas pela Resolução do CNS (Conselho Nacional de Saúde) n 466/12, para pesquisas envolvendo seres humanos.

\section{A educação de jovens e adultos como políticas públicas: encontros e legislações}

Ao analisar as diretrizes educacionais que norteiam a EJA nas últimas décadas, verificamos forte influência de interesses das classes dominantes no sistema educacional, onde está inserida essa modalidade de ensino. Esse fato tem impacto no processo educacional oferecido a esse público, pois é notório que a modalidade EJA de ensino está em segundo plano, conforme abordado por Camargo e Martinelli (2006). Tal afirmação refere-se a investimentos em oferta, infraestrutura, qualificação docente, dentre outras ações para a área da Educação de Jovens e Adultos.

O Estado os oferece para esse público apenas como possível remissão e/ou pagamento de dívidas sociais? Qual é o teor de responsabilidade para e pela cidadania entre "iguais"? Críticas sociais dessa natureza só poderão ser desenvolvidas através da educação consciente: educação na práxis, a qual significa ação - reflexão - ação. Essa abordagem é apresentada por Siqueira (2009) ao dizer que a EJA não existe por acaso, mas como forma de resgatar dívidas para com a população no que diz respeito ao direito de todos à educação básica, o qual foi estabelecido na Constituição Federal de 1988.

Jovens, adultos e idosos que procuram seu direito de estudar, trazem consigo histórias, origens e diferentes culturas; ademais, os motivos pelos quais buscam retomar os estudos variam de pessoa a pessoa. São necessárias reflexões críticas sobre esses apontamentos; para tanto, é importante fomentar diretrizes de apoio à sociedade com o objetivo de minimizar falhas no sistema educacional básico, o qual é direito de todos (SOARES, 2002). 
Os autores Naiff e Naiff (2008) afirmam que o retorno aos estudos por pessoas que não conseguiram concluir a Educação Básica no ensino regular pode refletir na busca por promoção social alcançada através de melhorias pessoais as quais incluem a recuperação da autoestima. Há pessoas que focam em qualificação profissional por necessidades impostas pelo mercado; contudo, a busca por conhecimento e cultura é um fator importante a ser considerado.

Os autores anteriormente mencionados também abordam o possível risco de ciclo vicioso no qual podem se envolver as pessoas que abandonam os estudos para trabalhar. Ao estarem ativas no mercado de trabalho, esses indivíduos percebem dificuldade em ascender profissionalmente em função de sua falta de qualificação, haja vista o fato de a qualificação vir, de maneira geral, através dos estudos. Essa condição marca gerações que, de certa forma, ficam "aprisionadas" ao trabalho informal. Novamente, torna-se evidente que a Educação de Jovens e Adultos é colocada em segundo plano, uma vez que a relação trabalho/estudo predomina entre pessoas que necessitam dela para completar sua formação ou que concluíram a formação básica por esta modalidade.

De certa forma, tal negligência governamental tornou-se uma "decepção" social que tem perdurado até o presente momento de nossa história. A falta de formação adequada, oriunda do déficit pedagógico apresentado pela modalidade de ensino para jovens e adultos, evidencia-se na própria oferta de empregos, a qual está cada vez mais criteriosa ao solicitar qualificações específicas. Soares (2002) apresenta uma abordagem crítica à EJA ao dizer que ressignificar com consciência é repensar essa modalidade de ensino de forma socialmente inclusiva, a partir de práticas pedagógicas que contemplem as diferenças, sem discriminação. A partir do momento que houver articulação de demandas estratégicas que sejam estabelecidas pelo poder público concomitantes à comunidade; essas poderão fazer diferença às pessoas que se encontram à "margem" da sociedade por fatores de desigualdades e continuam esperando oportunidades para ter formação digna e inserção social.

A PNAD Contínua, realizada em 2018 pelo IBGE, apresentou dados da realidade brasileira que evidenciam percentuais que vão desde instrução zero até inconclusões no processo de escolarização prevalentes na Educação Básica. Uma relevância significativa é dada à problemática da educação (IBGE, 2018), conforme Figura 1, na sequência: 
Figura 1- Percentual de pessoas de 25 anos de idade, ou mais, que concluíram, ao menos, a educação básica obrigatória, segundo sexo, cor ou raça, nas Grandes Regiões (\%)

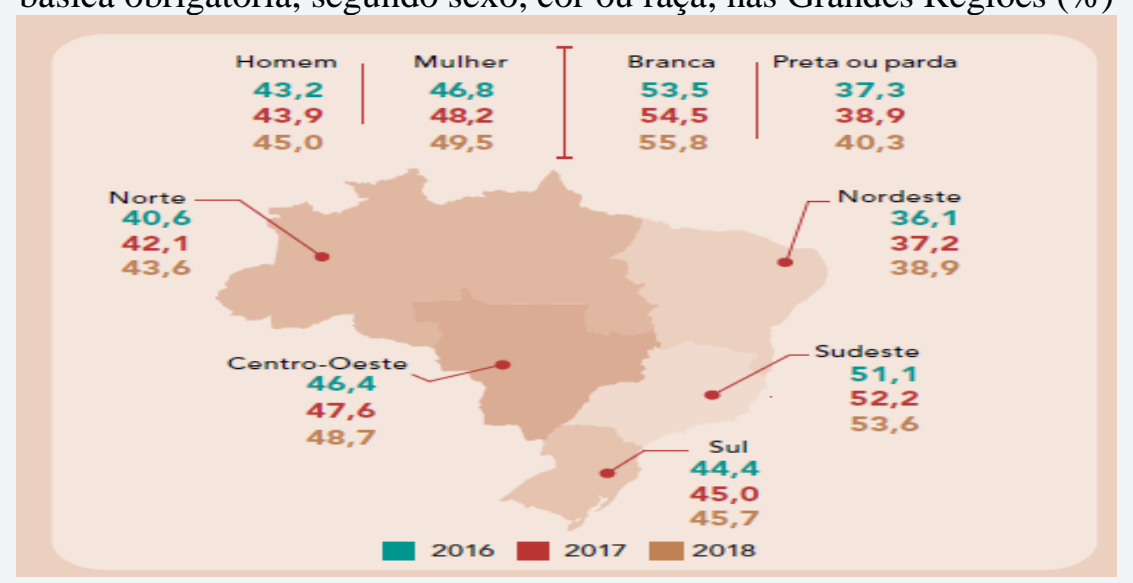

Fonte: IBGE, 2018

Ao analisar a Figura 1 quanto a particularidades como sexo e raça, as taxas registradas entre homens e mulheres quase dobram, assim como acontece entre pessoas brancas e negras ou pardas. O acesso à educação de qualidade é garantido por lei em nosso país; porém, como prática social - considerando raça, sexo e igualdade de classes - ainda parece utópico diante das modificações políticas em curso, nas últimas décadas.

Apesar de todos os avanços e aspectos positivos em relação à Educação de Jovens e Adultos no cenário nacional, Paiva (2006) diz que ainda é recorrente a visão de que a educação pela EJA busca recuperar o tempo perdido por aqueles que não aprenderam a ler e a escrever - isto é, retornar à escola, no tempo presente, para fazer o que não pôde ser feito na infância. Só ao pensar no âmbito social é possível chegar à concepção do direito de todos/as à educação, e ao direito de aprender por toda a vida.

A modalidade da EJA teve origem no século passado e fundamenta-se na alfabetização (KUENZER, 2005). Porém, fatores sociais e mercadológicos pautados na globalização, evidenciam a necessidade emergente de uma formação muito mais completa do que aquela disponibilizada atualmente. Hoje, com a presença das tecnologias de informação e comunicação, a necessidade de qualificação é muito mais do que o saber ler e escrever; interações sociais também estão evidentes em redes de informação.

Ainda, segundo Kuenzer (2005), a formação intelectual atual vai além das paredes da escola, uma vez que o mundo pode ser acessado à distância.

Quando percebemos estar inseridos em uma sociedade informatizada, estabelece-se um outro grande desafio a essa modalidade de ensino. Uma vez que existem sérias questões sociais devido às exclusões evidenciadas pelos próprios sistemas educacionais, as quais só 
aumentam nossa responsabilidade como educadores na ressignificação do sistema de ensino especificamente para que a EJA seja, na prática, inclusiva.

\section{O processo formativo e a condição de estudante da EJA: da escolarização à prática social}

Ao articular-se o regime de colaboração, expresso no plano nacional de educação, entre todos os setores sociais envolvidos, observa-se uma aproximação positiva da formação na práxis, pois é necessário desenvolver-se uma "consciência" inclusiva.

Baseado em tal conjuntura, seria interessante que a EJA tivesse prioridade nacional na ressignificação curricular, dado o alto número de analfabetos ou de pessoas que não concluíram seus estudos no ensino regular na idade apropriada, segundo dados apresentados em pesquisas do IBGE (2018). As implicações do plano nacional da educação, com vistas a uma escola democrática, continuam sendo um desafio que envolve uma visão sistêmica de classes (IBGE, 2018).

Segundo Paiva (1987), a EJA existe para as camadas populares da sociedade e sua gratuidade deve ser garantida a todos. Por fazer parte de uma educação popular, a educação via EJA, geralmente, inclui aulas noturnas para alcançar trabalhadores ainda sem formação básica. No entanto, a autora complementa, ao afirmar que, ainda há a desconsideração com o pedagógico em virtude de burocracias administrativas. Segundo ela, ainda mais grave, são as sedimentações dos sistemas referentes às ordens dadas e às decisões unilaterais em vigor que educadores da EJA são obrigados a seguir.

As políticas educacionais da EJA não têm conseguido acompanhar os novos tempos, assim como não tem atualizado os currículos de forma adequada a essa modalidade de ensino. Tais ajustes devem ser contínuos e voltados à realidade emergente. Essas evidências encontram-se no Plano Nacional da Educação e no Plano Estadual da Educação. Das e Poole (2008) dizem que incentivos a políticas educacionais voltados à valorização de pessoas que estudam por meio da EJA, com o objetivo de desenvolverem-se intelectualmente, ainda são raros.

Há carência de diretrizes que busquem transformar o/a aluno/a dessa modalidade em agente transformador de seu meio e realidade social. Os conteúdos ministrados não "alcançam" as necessidades reais de tais pessoas. Segundo os autores, outras modalidades de ensino, mesmo em outros países, também evidenciam esse fato. 
A carga horária reduzida da modalidade EJA é um outro fator a demonstrar a complexidade desse sistema, pois depara-se com a dificuldade de sua ampla e igualitária realização. Além do mais, os conteúdos selecionados, muitas vezes, não têm aderência à realidade dos alunos, os quais trazem consigo uma bagagem de vida e vivências mercadológicas diferenciadas daquelas do público proveniente da escola regular. A ressignificação do currículo deve focar a formação mais ampla em contextos culturais, históricos e humanos, além de aproximar experiências individuais e sociais a temáticas que promovam maior consciência científica e proximidade a tecnologias, para sua aplicabilidade prática. Portanto, dada a tarefa hercúlea, carga horária seria mais produtiva se focasse na autonomia dos estudantes da Educação de Jovens e Adultos.

Freire (2000), ao abordar a educação como prática da liberdade, evidencia a necessidade de aproximação dos saberes individuais através de trocas coletivas enriquecedoras na escola e no mundo. As temáticas científicas ganham um significado diferenciado ao serem inseridas em contextos práticos, do dia a dia, que caminhem a par com vivências pessoais. Logo, há que haver fôlego novo para a aprendizagem, pois ela desperta a consciência acerca do papel da ciência, da tecnologia e, principalmente, de cada indivíduo como "ser fazedor de sua história", verdadeiramente, incluído na sociedade.

Usualmente, sistemas educacionais trabalham conteúdos, por vezes, fragmentados, o que é um empecilho inegável a uma visão ampla de mundo, a partir do conhecimento. A falta de integração entre conteúdos, muitas vezes, fica clara em atividades práticas, que não reproduzem possíveis práticas sociais ou que, pior, contribuem fortemente para a alienação de corpo discente. Segundo Kuenzer (2005), a desconexão entre conteúdos é uma prática de viés econômico, que alimenta a desigualdade social; é uma forma de manter-se a exclusão social de pessoas que concluem seus estudos pela modalidade da EJA.

A busca por novos paradigmas teóricos e pedagógicos voltados à EJA, evidencia a dificuldade em formar pessoas que ingressam nessa modalidade de ensino. Os motivos estão nos distintos contextos sociais, na diferença entre faixas etárias, nas diversas profissões adotadas por alunos EJA e em necessidades mercadológicas, entre outras situações do dia a dia, tais como responsabilidade familiar como a criação dos filhos. As propostas didáticopedagógicas disponíveis, em sua grande maioria, encontram-se distantes da realidade vivida por esse público, pois tais indivíduos trazem consigo particularidades que precisam ser consideradas, utilizadas em momentos de troca de saber em sala de aula, e não mantidas à distância do ambiente escolar. Logo, "seus valores, suas habilidades, seus conhecimentos 
adquiridos por suas vivências jamais deverão ser ignorados, mas alcançados e interligados às ciências (FREIRE, 1980, p. 82-83)".

É importante manter-se diálogos críticos, conscientes, que se materializem nas ações advindas de políticas públicas, de diretrizes educacionais, do PNE, dos Planos Estaduais, dos Conselhos, dos Ministérios, das redes municipais, assim como de tantos outros órgãos da sociedade. Tal processo pode dar luz a problemas reais e desencadear ações em prol de uma sociedade livre, justa, igualitária, na qual todos têm os mesmos direitos e oportunidades. Estímulo, entre pares, para a produção, a disseminação e a reflexão do conhecimento torna toda a mudança possível.

Strelhow (2010) afirma que o Brasil no que diz respeito às políticas educacionais voltadas à EJA, ainda não conseguiu, na prática, oferecer educação para todas as pessoas, como garante a Constituição Federal. Milhares de pessoas espalhadas pelo Brasil ainda não foram alcançadas por esse direito básico à educação.

Na Paraíba, conforme consta no PEE (Plano Estadual de Educação) 2015-2025, o FEPAD-PB (Fórum Estadual Permanente de Apoio à Formação dos Profissionais do Magistério da Educação Básica da Paraíba), que está em vigor desde o PEE - com vigência anterior -, tem sido um aporte de debates acerca da EJA. Conforme descrito no próprio site do FORUMEJA (2011), esses fóruns levantam temáticas reflexivas sobre "o que" e "como" a formação docente vem se constituindo no estado.

O Governo da Paraíba, por meio da SEECT (Secretaria de Estado da Educação e da Ciência e Tecnologia), apresentou o projeto SER EJA, lançado no segundo semestre de 2018. Esse projeto foi um grande incentivador para os alunos da Educação de Jovens e Adultos. Depois de seu lançamento, houve maior procura pelo curso, pois o número de matrículas aumentou em 33\%, conforme apresentado no site do governo do estado. (PARAÍBA, 2020). O projeto contou com a participação de 28 escolas, durante o plano piloto: das quais 25 Escolas Cidadãs Integrais e 3 escolas que disponibilizam a modalidade EJA (presencial e semipresencial) nas cidades de João Pessoa, Campina Grande, Bayeux e Santa Rita. O site do governo estadual registrou 3.500 alunos beneficiados com o projeto SER EJA Cidadã em 2018; em 2019, o número de matrículas subiu para 4.669. Hoje, são mais de 58 mil alunos EJA em toda a rede Estadual da Paraíba (PARAÍBA, 2020).

A centralidade da proposta metodológica do projeto SER EJA Cidadã está nos direitos dos estudantes, com vistas ao protagonismo pedagógico à Educação de Jovens e Adultos, evidenciando, assim, as trajetórias vividas pelo alunado. $\mathrm{O}$ incentivo à participação desses 
estudantes no projeto é um agente integrador no processo educacional entre discentes e docentes. Experiências, de ambos grupos, são trazidas ao contexto pedagógico e trocadas entre eles.

O projeto ainda prevê o processo de formação inicial, e continuada, o que evidencia a teoria da problematização. Novamente, os fóruns aparecem como importantes fomentadores de conhecimento, pois os estudantes participam na escolha de temas para encontros agendados para discussões pedagógicas sobre as temáticas elencadas. Tais encontros são parte do projeto SER EJA Cidadã; professores mediam as reuniões através da interdisciplinaridade de conteúdos apontados durante as discussões, levando em consideração as trajetórias de vida dos estudantes envolvidos com o projeto (PARAÍBA, 2020). No total, 351 professores de municípios envolvidos no projeto, receberam formação continuada em serviço, para dar fôlego aos fóruns da Paraíba.

Cursos semipresenciais à EJA, disponibilizados pela secretaria da Educação, é outro tema abordado pelo governo da Paraíba. Essa proposta está em fase inicial e foi apresentada em Seminários Estaduais de Jovens e Adultos, e o primeiro da série foi realizado em julho de 2019, conforme noticiado no site do governo do Estado (PARAÍBA, 2020). A nova proposta visa possibilitar que estudantes permaneçam no mercado de trabalho, embora tenham-se conhecimento de que não conseguirão estar presentes todos os dias nas aulas; porém, devem poder concluir seus estudos fora da escola, com o auxílio de tecnologias da informação e de comunicação em rede.

Para tanto, a proposta semipresencial deve ajustar-se à realidade dos estudantes EJA, de forma a adequar-se, também, ao mercado de trabalho e às atuais tecnologias. As metodologias didático-pedagógicas inovadoras e atraentes precisam ser colocadas em prática, a fim de garantir o aprendizado desse público, pois ele terá desafios ainda maiores, no contexto de aulas semipresenciais, do que os encontrados no ensino presencial.

Introduzir tecnologias como internet, plataformas e materiais disponíveis em rede de Educação a distância, mesmo que parcialmente, requer a criação de aulas específicas e qualificação específica para docentes e alunos. Estudantes que chegam à escola sem conhecimento prévio da internet, necessitam de acompanhamento docente adequado, aulas diferenciadas, que estejam em conformidade com o grau de analfabetismo apresentado pelo aluno.

Aulas básicas introdutórias sobre como usar as tecnologias de informação e comunicação, o computador, a internet e demais ferramentas disponíveis "online", são 
imprescindíveis para que tais alunos(as) consigam acessar conteúdos disponibilizados em rede, ao atenderem à modalidade de ensino semipresencial. A proposta apresentada pela Secretaria de Educação do Estado da Paraíba (2019) ainda está em estágio embrionário; e é tema de debates entre coordenadores do processo educativo em âmbito estadual (PARAÍBA, 2020).

Portanto, os docentes precisam estar preparados para o novo desafio. Nesse sentido, Miranda (2008) aborda a importância da formação inicial de professores e de sua contribuição para profissionais da Educação de Jovens e Adultos; em suas próprias palavras:

Uma proposta de formação requer acima de tudo uma reflexão acerca da sua intencionalidade, dos seus pressupostos teóricos, filosóficos, metodológicos e outros. Pensar o processo inicial de formação docente implica, acima de tudo, rever e analisar as intencionalidades que permeiam esse processo, ou seja, o seu currículo. Este por sua vez não acontece no vazio, é perpassado pelas relações sociais, históricas, culturais, afetivas, e outras, que poderíamos mencionar. (MIRANDA, 2008, p. 79).

Logo, empreendimentos que ainda estejam no campo das ideias, demandam ações que sejam tomadas antes mesmo de sua implementação, como é o caso da EJA, na modalidade semipresencial, na Paraíba. Nesse caso, são necessárias adequações curriculares, pois tratamse de processos educacionais complexos, que exigem que professores e estudantes, nessa modalidade, internalizem as novas concepções em prol da construção de um processo de escolarização inclusivo para todos os seus atores sociais.

\section{Resultados da Pesquisa}

A pesquisa foi realizada in loco, após entrar em campo, em julho de 2019, através de contatos feitos com responsáveis pela direção e coordenação do núcleo da EJA, com a secretaria e monitores do Centro de Educação, da UFPB (CE), no município de João Pessoa. Após a pesquisa ser autorizada pelo Comitê de Ética, sob no $3.531 .158^{2}$, em agosto de 2019, foram feitos os contatos com os alunos(as) da EJA; a pesquisa de campo foi concluída em dezembro de 2019, no final do semestre.

A EJA, nível médio, foi escolhida pelos pesquisadores, pois possibilitava a investigação das experiências trazidas pelos alunos(as) nessa modalidade de ensino. A intenção foi ampliar os aspectos políticos e sociais na etapa de conclusão da Educação Básica.

\footnotetext{
${ }^{2}$ http://plataformabrasil.saude.gov.br/login.jsf CAAE: 18873719.5.0000.5188.
} 
A maioria dos participantes dessa modalidade de ensino, que estavam incluídos do estudo, são trabalhadores comprometidos com seus horários de trabalho. Portanto, muitos enfrentaram dificuldades para chegar ao núcleo; monitores ajudaram na escolha do horário de aula ideal para a realização da pesquisa. Os respectivos professores foram consultados sobre qual seria o melhor momento para a abordagem, de forma que a pesquisa não prejudicasse os estudantes.

Mesmo após esclarecimentos sobre a pesquisa e sobre a importância do estudo, nem todos os matriculados no EJA, e presentes no ato da pesquisa, quiseram participar. Alguns alegaram não ter interesse e outros não se dispuseram a assinar o TCLE após lerem o documento. Mesmo com a resistência de alguns, o percentual necessário para a realização da pesquisa foi atingido.

Os 25 estudantes que aceitaram participar do estudo corresponderam a $20 \%$ dos alunos matriculados no núcleo, no segundo semestre de 2019. Dos alunos que aceitaram participar da pesquisa, e que assinaram o TCLE (Termo de Consentimento e Livre Esclarecimento), 11 identificaram-se como sendo do sexo masculino e 14, como do sexo feminino. Participantes da amostra estavam no grupo de idade de 18 a 57 anos.

O roteiro de perguntas, por vezes, endereçava a mesma tratativa; porém, com abordagens diferentes, a fim de extrair informações de natureza social, intrínsecas à formação almejada por esse público específico, através da EJA, a despeito de suas vivências pessoais e particularidades.

A tabulação de "a" a " $g$ " tem enfoque abrangente e condensa ideias relevantes, para compor resultados qualitativos. As questões foram apresentadas aos participantes matriculados na EJA do Centro de Educação da UFPB, a fim de identificar o seu perfil. Vejamos:

a. Motivo de ter escolhido a modalidade EJA;

b. Incentivo governamental para a EJA;

c. Dificuldades encontradas para buscar formação em idade regular;

d. Pontos positivos e/ou negativos da EJA;

e. Expectativas para o futuro;

f. Direito ao estudo: Vivências como cidadão;

g. Inclusão ou exclusão: O que dizer sobre desigualdade social?

A tabulação, a partir da letra "h", apresentou questões relativas a vivências pessoais, as quais contribuem com outras especificidades do perfil dos participantes. 
h. Meio de transporte utilizado para chegar ao curso;

i. Adaptação ao estudo e ao trabalho;

j. Vivências/convivências entre colegas e professores;

k. Se existe ou existiu incentivo da família para voltar aos estudos;

1. Se existe interação de assuntos entre disciplinas;

m. Se as aulas são consideradas monótonas ou dinâmicas;

n. Se o aprendizado pela EJA tem sido útil, no dia-a-dia, e tem ajudado no trabalho;

o. Avaliação e recuperação de estudos abordados na EJA;

p. Quais as maiores dificuldades em sala de aula;

q. Se estudar com colegas de idade diferente da sua ajuda ou atrapalha;

r. Se sente excluído ou não ao dizer que é estudante da EJA;

s. Outras questões levantadas pelos próprios participantes: lanche, material didático, infraestrutura.

As ideias centrais das respostas dos estudantes estão representadas no discurso-síntese, abaixo - o discurso está na primeira pessoa do singular -, de acordo com questionamentos levantados na tabulação de "a" a "s". O excerto é utilizado como pensamento "geral”, baseado na técnica do DSC, para evidenciar o pensamento do grupo de participantes fosse funciona como um discurso individual:

\footnotetext{
“ $a$ ”. Um grande incentivador para desejar completar a formação básica é em retornar ao mercado de trabalho. Preciso de curso específico, e consequentemente a formação básica, nível médio é uma exigência mínima. A escolha pela EJA deve-se a minha idade. " $\boldsymbol{h}$ " Utilizo ônibus para vir estudar. “ $\boldsymbol{b}$ ” Não vejo incentivo governamental para a Educação de Jovens e Adultos. "i " Estudar e trabalhar é muito difícil. " $s$ " Sinto falta de merenda, pois vimos que é nosso direito na legislação que a professora apresentou. É dever legal a oferta do lanche, já que viemos de diferentes lugares e muitos chegam direto do trabalho, com fome. É muito triste tudo isso.

" $s$ " Gostaria que existisse uma infraestrutura melhor para os alunos da EJA, sinto falta de salas fixas, de livros, apostilas. Os professores precisariam de uma capacitação melhor para poder atender com maior qualidade as nossas necessidades, principalmente aos que possuem necessidades especiais de modo geral.

“c” As dificuldades que se fizeram presentes pra mim, de estudar em idade apropriada foram as distâncias para deslocamentos e falta de dinheiro na família. Precisei trabalhar cedo. “ $k$ ” Não tive incentivo para voltar a estudar nos lugares onde trabalhei.

"l” Vejo a EJA muito fragmentada pelo fato de não haver interação dos assuntos entre as disciplinas. “ $\boldsymbol{m}$ ” As aulas até são boas, dinâmicas, mas sinto falta de prática social. “j” Os professores não medem esforços para dar o seu melhor e isto tem me ajudado muito com retorno de aprendizagem. $\mathrm{O}$ convívio é bom entre colegas. " $\boldsymbol{n}$ ” Depois que voltei a estudar tenho me desenvolvido melhor no meu dia a dia.
} 
" $d$ " Avalio a EJA como positiva, pois se não fosse a EJA, não teria a chance de terminar meus estudos. "o" Eu recupero meus estudos respondendo as atividades propostas pelos professores. " $p$ ” Minha maior dificuldade está nas disciplinas de Física, Química e Matemática, pois "não entendo a forma deste ensino". "q" Estudar com colegas de idade diferente ajuda na compreensão geral. Ajuda muito. A gente se ajuda bem.

Desejo que por esta formação possa melhorar minha vida profissional e chegar ao Ensino Superior. Meu sonho. " $e$ ” Minhas expectativas para o futuro é de que haja uma maior inclusão social. " $f$ ” Me sinto uma cidadã com direitos para estudar. Os fatores negativos da EJA são a falta de lanche e a falta de passagens, pois muitos alunos não retomam os estudos por não terem condições de chegar aos locais de aula ou quando vêm, chegam de seus trabalhos sem comer, e acabam desistindo por falta de ajuda.

“d” Os professores são ponto positivo na EJA, pois ensinam muito bem, e apesar de todas as dificuldades que a gente enfrenta existe aprendizagem, mas os professores também precisam "melhorar mais". " $r$ " Não me sinto excluída ao dizer que estudo na EJA. Sou grata em me sentir incluída na sociedade graças a que me ajudou, e a EJA e aos profissionais aqui do núcleo.

" $g$ " Existe muita desigualdade social, sem nenhum incentivo para os menos favorecidos, desigualdade de renda, falta de alimentação. " $s$ ” Já presenciei várias situações de colegas que vêm de longe, "a pé", para estudar e sem se alimentar. Precisamos de melhorias já! Mais inclusão! Mais incentivos!

Essa síntese representa o discurso coletivo, aponta para questões-chave, contempla todas as discussões dispostas no roteiro proposto, que foram levantadas nos três grupos que participaram da pesquisa. As letras em negrito e itálico correspondem às questões indicadas na tabulação de "a" a "s" - são abrangentes e singulares, pois representam os participantes.

O quadro 1 apresenta outras especificidades dos resultados obtidos sobre o perfil dos participantes. As informações são baseadas em questões tabuladas anteriormente, a partir da letra "h", de acordo com a técnica do DSC.

Quadro 01 - Especificidades d o perfil dos participantes

\begin{tabular}{|c|c|c|}
\hline Questões levantadas & Expressões-chave do DSC & Outras respostas \\
\hline $\begin{array}{c}\text { Meio de transporte utilizada } \\
\text { para chegar ao curso }\end{array}$ & Ônibus & Moto ou a pé \\
\hline $\begin{array}{c}\text { Adaptação ao estudo e } \\
\text { trabalho }\end{array}$ & Cansativo & Normal \\
\hline $\begin{array}{c}\text { Vivências/convivências } \\
\text { entre colegas e professores }\end{array}$ & Muito boa & Não coleguismo \\
\hline $\begin{array}{c}\text { Se existe ou existiu } \\
\text { incentivo da família para } \\
\text { voltar aos estudos }\end{array}$ & Sim & - \\
\hline $\begin{array}{c}\text { Se existe interação de } \\
\text { assuntos entre disciplinas }\end{array}$ & Dinâmicas e participativas & Monótonas para disciplinas com \\
\hline $\begin{array}{c}\text { Se álculos aulas são consideradas } \\
\text { monótonas ou dinâmicas }\end{array}$ & Sim. Melhorou bastante & Indiferente \\
\hline $\begin{array}{c}\text { Se o aprendizado pela EJA } \\
\text { tem sido útil no dia-a-dia e }\end{array}$ & \multicolumn{2}{|c|}{} \\
\hline
\end{tabular}




\begin{tabular}{|c|c|c|}
\hline se tem ajudado no trabalho & & \\
\hline $\begin{array}{l}\text { Avaliação e recuperação de } \\
\text { estudos utilizados na EJA }\end{array}$ & Provas, trabalhos & - \\
\hline $\begin{array}{c}\text { Quais as maiores } \\
\text { dificuldades em sala de aula }\end{array}$ & $\begin{array}{l}\text { Sono, disciplinas com cálculos, } \\
\text { cansaço, fome }\end{array}$ & - \\
\hline $\begin{array}{c}\text { Se estudar com colegas de } \\
\text { idade diferente da sua ajuda } \\
\text { ou atrapalha }\end{array}$ & Ajuda & - \\
\hline $\begin{array}{l}\text { Se sente excluído ou não ao } \\
\text { dizer que é estudante da } \\
\text { EJA no local de trabalho }\end{array}$ & Não & $\begin{array}{c}\text { Exclusão no campus por estudantes da } \\
\text { Graduação e Pós-graduação }\end{array}$ \\
\hline $\begin{array}{c}\text { Outras questões levantadas } \\
\text { pelos próprios participantes: } \\
\text { lanche, material didático, } \\
\text { infraestrutura }\end{array}$ & $\begin{array}{l}\text { Não é disponibilizado lanche } \\
\text { para os estudantes da EJA. } \\
\text { Chegam direto do trabalho, } \\
\text { com fome. Esse fato dificulta a } \\
\text { aprendizagem e a concentração }\end{array}$ & $\begin{array}{c}\text { Carência de materiais didáticos e apoio } \\
\text { para o trabalho dos próprios } \\
\text { professores. } \\
\text { Falta de interesse por parte dos } \\
\text { próprios estudantes. } \\
\text { Estudar e trabalhar é muito cansativo. } \\
\text { Não ter salas próprias no núcleo no } \\
\text { Campus, pois são compartilhadas por } \\
\text { outros cursos }\end{array}$ \\
\hline
\end{tabular}

Fonte: Núcleo da EJA/UFPB/Pesquisa com grupo focal/2019.

As expressões-chave, destacadas no quadro 1, aparecem, repetidamente, nas falas dos participantes, e configuram a característica do método utilizado como discurso do sujeito coletivo. As demais questões levantadas pelos estudantes não são menos importantes, pois apresentam críticas ao sistema educacional da Educação de Jovens e Adultos; por isso, estão descritas no quadro, na letra "s".

Os pontos positivos identificados no quadro 1 estão nas seguintes declarações: boa convivência entre colegas e professores; terem incentivos de familiares para estudar; as aulas são consideradas dinâmicas e participativas; identificam interação entre assuntos estudados; o aprendizado na EJA contribui para o dia a dia; estudar com colegas de diferentes idades ajuda; não se sentem excluídos ao dizer que estudam na EJA.

Os pontos negativos que ganharam destaque foram: falta do lanche, que deveria ser oferecido gratuitamente pelo núcleo - os alunos sentem fome, o que, segundo eles, interfere na concentração para aprender e compromete o rendimento nas aulas; cansaço ao conciliar trabalho e estudo e distâncias percorridas para chegar ao núcleo. Os participantes disseram sentir maior dificuldade em disciplinas do núcleo das Ciências Exatas.

Apesar desses alunos/as não se considerarem excluídos/as ao revelarem-se como estudantes da EJA, sentem-se excluídos pelos estudantes de graduação e de pós-graduação, no Campus do núcleo. Há olhares de menosprezo, falta de cumprimentos, de cordialidade, em um ambiente que tem como prerrogativa fomentar a educação. Esta observação chegou como um desabafo. 
Outro ponto negativo, ausente no discurso geral, mas levantado por alguns participantes, é a falta de material didático e de apoio para o trabalho, tanto para eles (os alunos) quanto para os docentes. Não ter salas próprias para o curso, no núcleo do Campus, também foi um fator desgastante, para alguns, pois as salas são compartilhadas com cursos de graduação e de pós-graduação. Segundo eles, quem estuda nessa modalidade fica em segundo plano na alocação das salas. Tal fato também atrapalha o tempo das aulas, uma vez que os estudantes têm que vagar até achar uma sala disponível para uso - isso acontece a cada período- além disso, também precisam aguardar que os monitores informarem para onde irão.

As falas dos alunos, mais do que fornecer informações para a pesquisa, sinalizam as vozes e condições enfrentadas pelos estudantes EJA, os quais trazem bagagens e experiências adquiridas fora da sala de aula, em seus trabalhos e com suas famílias. Contudo, demonstram persistência em buscar continuamente os estudos, ainda que em um sistema educacional que, às vezes, corrobora com a exclusão social, cultural e estudantil.

\section{Os documentos orientadores da EJA e os achados da pesquisa: encontros e desencontros}

A análise de dados esteve presente em cada etapa da pesquisa, pois Lüdke e André (2005) afirmam que as diferentes fases se cruzam em diferentes momentos, uma vez que informações aparecem de forma não-linear. Sendo assim, ao analisar as possíveis conexões estabelecidas entre essa pesquisa e as políticas educacionais da modalidade da EJA, percebese os encontros e desencontros, descritos no quadro 2. A análise foi executada pelo método DSC, e utilizou questões da pesquisa aplicada aos participantes.

Quadro 2 - Questões da pesquisa sobre o Plano Estadual de Educação da Paraíba (2015 - 2025), a Constituição Federal (1988), a Lei no 11.947/2009 e a LDBEN 9.394/1996

\begin{tabular}{|c|c|c|}
\hline $\begin{array}{c}\text { Questões } \\
\text { levantadas }\end{array}$ & $\begin{array}{c}\text { Discurso do Sujeito } \\
\text { Coletivo }\end{array}$ & $\begin{array}{c}\text { Políticas Educacionais da EJA/Plano } \\
\text { Estadual de Educação da Paraíba (2015 } \\
-\mathbf{2 0 2 5} \text { ), na Lei no 11.947/2009 e na } \\
\text { LDBEN no }\end{array}$ \\
\hline \multirow{2}{*}{$\begin{array}{c}\text { Motivos da escolha } \\
\text { pela EJA }\end{array}$} & $\begin{array}{c}\text { Fator idade, necessidade de } \\
\text { concluir o nível médio, } \\
\text { exigências do trabalho e para } \\
\text { ingressar em formação } \\
\text { técnica ou superior }\end{array}$ & $\begin{array}{c}\text { 4.10. Redimensionar e ampliar a oferta de ensino } \\
\text { médio nos turnos diurno e noturno, bem como a } \\
\text { distribuição territorial das escolas de ensino } \\
\text { médio, de forma a atender a toda demanda, de } \\
\text { acordo com as necessidades específicas dos (as) } \\
\text { alunos (as); 4.11. Desenvolver formas } \\
\text { alternativas de oferta do ensino médio, garantida } \\
\text { a qualidade, para atender aos (às) filhos (as) de } \\
\text { profissionais que se dedicam a atividades de } \\
\text { caráter itinerante (PEE) }\end{array}$ \\
\hline
\end{tabular}




\begin{tabular}{|c|c|c|}
\hline $\begin{array}{c}\text { Incentivo } \\
\text { governamental para a } \\
\text { EJA }\end{array}$ & $\begin{array}{c}\text { Existe na oferta do curso, } \\
\text { porém com lacunas } \\
\text { geográficas, pois não há } \\
\text { oferta em várias regiões do } \\
\text { estado da Paraíba. Não existe } \\
\text { incentivo governamental, no } \\
\text { geral, pois faltam benefícios } \\
\text { como transporte ou lanche, } \\
\text { previstos na legislação }\end{array}$ & $\begin{array}{l}\text { 9.10. Articular as ações da educação de jovens e } \\
\text { adultos com as políticas sociais das áreas da } \\
\text { saúde, da assistência social, da cultura, do } \\
\text { desporto e do lazer, fortalecendo o atendimento } \\
\text { em rede (PEE) }\end{array}$ \\
\hline $\begin{array}{l}\text { Dificuldade em } \\
\text { concluir a formação } \\
\text { em idade regular }\end{array}$ & $\begin{array}{l}\text { Escola em educação básica } \\
\text { muito distante } \\
\text { geograficamente. Precisar } \\
\text { trabalhar. }\end{array}$ & $\begin{array}{l}\text { 4.9. Instituir, com a colaboração da União e dos } \\
\text { municípios, programas de educação e de cultura } \\
\text { para a população urbana e do campo de jovens, } \\
\text { na faixa etária de } 15 \text { a } 17 \text { anos, e de adultos, com } \\
\text { qualificação social e profissional para aqueles } \\
\text { que estejam fora da escola e com defasagem no } \\
\text { fluxo escolar (PEE) }\end{array}$ \\
\hline $\begin{array}{l}\text { Inclusão ou exclusão: } \\
\text { o que dizer sobre } \\
\text { desigualdade social }\end{array}$ & $\begin{array}{l}\text { Incluído na sociedade, porém } \\
\text { a desigualdade social existe; } \\
\text { sem incentivos palpáveis para } \\
\text { os menos favorecidos, como } \\
\text { desigualdade de renda, falta } \\
\text { de alimentação e de trabalho } \\
\text { para todos. Presenciam } \\
\text { situações de pessoas que vêm } \\
\text { de longe, “a pé”, para } \\
\text { estudar, sem se alimentar. } \\
\text { São necessários mais } \\
\text { incentivos para combater a } \\
\text { desigualdade social }\end{array}$ & $\begin{array}{l}\text { 9.8. Implementar programas de capacitação } \\
\text { tecnológica para a população de jovens e adultos } \\
\text { com baixo nível de escolarização formal e para } \\
\text { os alunos com deficiência, articulando a rede } \\
\text { federal de educação profissional, científica e } \\
\text { tecnológica, universidades, cooperativas, } \\
\text { associações, fundação de apoio a deficientes, } \\
\text { que favoreçam a efetiva inclusão social e } \\
\text { produtiva dessa população (PEE). } \\
\text { Constituição Federal, art. 208: Dever do Estado } \\
\text { com a educação será efetivado mediante a } \\
\text { garantia de: [...] VII - atendimento ao educando, } \\
\text { em todas as etapas da educação básica, por meio } \\
\text { de programas suplementares de material } \\
\text { didático-escolar, transporte, alimentação e } \\
\text { assistência à saúde (BRASIL, 1988) }\end{array}$ \\
\hline $\begin{array}{l}\text { Meio de transporte } \\
\text { utilizado para chegar } \\
\text { ao curso: ônibus }\end{array}$ & $\begin{array}{c}\text { Não existe ajuda de custo } \\
\text { para o transporte }\end{array}$ & $\begin{array}{c}\text { Os alunos de ensino médio e EJA das redes } \\
\text { estadual e municipal agora terão direito à } \\
\text { alimentação e transporte. A medida está prevista } \\
\text { na Lei } n^{\circ} 11.947 \text {, criada no dia } 16 \text { de junho após } \\
\text { o presidente em exercício, José Alencar, assinar } \\
\text { o Projeto de Lei } \text { n }^{\circ} 8 / 2009 \text {, transformando a } \\
\text { Medida Provisória } n^{\circ} 455 \text { em lei (Lei n }{ }^{\circ} \\
11.947 / 2009)\end{array}$ \\
\hline $\begin{array}{c}\text { Adaptação ao estudo e } \\
\text { trabalho }\end{array}$ & Cansativo & $\begin{array}{l}\text { 9.5. Ofertar os processos de alfabetização } \\
\text { respeitando a sua cultura, modo de vida, e suas } \\
\text { especificidades em termos de aprendizagem, } \\
\text { com base em concepções inclusivas e equidade, } \\
\text { bem como articulando ao mundo do trabalho } \\
\text { (PEE) }\end{array}$ \\
\hline $\begin{array}{l}\text { Se existe interação de } \\
\text { assuntos entre } \\
\text { disciplinas }\end{array}$ & Sim & $\begin{array}{l}\text { 10.7. Estimular a diversificação curricular da } \\
\text { EJA, articulando a formação básica e a } \\
\text { preparação para o mundo do trabalho, } \\
\text { estabelecendo inter-relações entre teoria e } \\
\text { prática, nos eixos da ciência, do trabalho, da } \\
\text { tecnologia, da cultura e cidadania (PEE) }\end{array}$ \\
\hline $\begin{array}{l}\text { Se o aprendizado pela } \\
\text { EJA tem sido útil no } \\
\text { dia a dia e se tem } \\
\text { ajudado no trabalho }\end{array}$ & Sim & $\begin{array}{c}\text { No que se refere à EJA Integrada à educação } \\
\text { profissional, a LDBEN define, no seu Art. } 1^{\circ}, \S \\
2^{\circ}, \text { que "a educação escolar deverá vincular-se } \\
\text { ao mundo do trabalho e à prática social" (Lei n } \\
9.394 / 1996)\end{array}$ \\
\hline
\end{tabular}




\begin{tabular}{|c|c|c|}
\hline $\begin{array}{c}\text { Quais as maiores } \\
\text { dificuldades em sala de } \\
\text { aula }\end{array}$ & $\begin{array}{l}\text { Sono, disciplinas com } \\
\text { cálculos, cansaço, fome }\end{array}$ & $\begin{array}{c}\text { Os alunos de Ensino Médio e EJA das redes } \\
\text { estadual e municipal agora terão direito à } \\
\text { alimentação e transporte. A medida está prevista } \\
\text { na Lei n } 11.947 \text {, criada no dia } 16 \text { de junho de } \\
2009 \text { após o presidente em exercício, José } \\
\text { Alencar, assinar o Projeto de Lei n }{ }^{\circ} 8 / 2009 \text {, } \\
\text { transformando a Medida Provisória } n^{\circ} 455 \text { em } \\
\text { lei (Lei } \text { n }^{\circ} 11.947 / 2009 \text { ) }\end{array}$ \\
\hline $\begin{array}{c}\text { Outras questões } \\
\text { levantadas pelos } \\
\text { próprios participantes: } \\
\text { lanche, material } \\
\text { didático }\end{array}$ & $\begin{array}{c}\text { Não é oferecido lanche para } \\
\text { os estudantes da EJA. } \\
\text { Chegam direto do trabalho, } \\
\text { com fome. Este fato dificulta } \\
\text { a aprendizagem e a } \\
\text { concentração. Carência de } \\
\text { matérias didáticos e apoio } \\
\text { para trabalho dos próprios } \\
\text { professores }\end{array}$ & $\begin{array}{l}\text { Constituição Federal, art. 208: “Dever do Estado } \\
\text { com a educação será efetivado mediante a } \\
\text { garantia de: [...] VII - atendimento ao educando, } \\
\text { em todas as etapas da educação básica, por meio } \\
\text { de programas suplementares de material } \\
\text { didático-escolar, transporte, alimentação e } \\
\text { assistência à saúde.” (BRASIL, 1988). } \\
\text { "8.5. Promover, em parceria com as áreas de } \\
\text { saúde e assistência social, a busca ativa, o } \\
\text { acompanhamento e o monitoramento do acesso } \\
\text { à escola, específicos para os segmentos } \\
\text { populacionais da EJA, bem como identificar os } \\
\text { motivos de absenteísmo escolar, de abandono e } \\
\text { de evasão, e colaborar com os municípios para a } \\
\text { garantia de frequência e apoio à aprendizagem, } \\
\text { de maneira a estimular a ampliação do } \\
\text { atendimento desses (as) estudantes na rede } \\
\text { pública regular de ensino.” (PEE). } \\
\text { “Os alunos de Ensino Médio e EJA das redes } \\
\text { estadual e municipal agora terão direito à } \\
\text { alimentação e transporte. A medida está prevista } \\
\text { na Lei no } 11.947 / 2009, \text { criada no dia } 16 \text { de junho } \\
\text { após o presidente em exercício, José Alencar, } \\
\text { assinar o Projeto de Lei no 8/2009, } \\
\text { transformando a Medida Provisória no } 455 \text { em } \\
\text { lei”" (Lei No } 11.947 / 2009 \text { ) }\end{array}$ \\
\hline
\end{tabular}

Fonte: Núcleo da EJA/UFPB/Pesquisa com grupo focal/2019.

Observando o DSC (discurso do sujeito coletivo) e a análise documental, com foco no estado da Paraíba, percebemos os aspectos positivos e negativos de fatores relevantes às políticas e práticas sociais. Os aspectos positivos são: inclusão social - afirmada pelos participantes e a disponibilidade da modalidade da EJA, apesar de tímida - em relação a áreas distantes dos grandes centros. Outro fator positivo foi o corpo docente do núcleo pesquisado, pois receberam elogios quanto a explanação dos conteúdos e a motivação que dão aos estudantes para concluírem seus estudos.

Questões negativas: o fator fome, expresso pela falta de merenda. Os alunos chegam ao núcleo direto de seus trabalhos, cansados e famintos; consequentemente, a falta da merenda prejudica ainda mais a concentração durante as aulas. O fator fome, nem deveria estar em pauta, pois, conforme garantido na Constituição Federal de 1988 e descrito na Lei n $^{\circ}$ 
11.947/2009, é dever do governo oferecer merenda a esse público, como também o auxílio para o transporte, pois ambos benefícios não chegam aos alunado no núcleo pesquisado.

O atual PEE (Plano Estadual de Educação) da Paraíba, com vigência até 2025, apresenta aportes para ampliar a disponibilidade, a promoção de parcerias com as áreas de saúde e assistência social, específicas para a população da EJA. Essas áreas devem identificar casos de absenteísmo escolar e fomentar a colaboração entre os municípios. O objetivo é garantir a frequência nas aulas, apoiar o aprendizado e ampliar o atendimento aos estudantes nesta modalidade.

Conforme exposto pelos participantes, existem negligências evidentes nesse sentido, desde o início da vigência do Plano Estadual de Educação apresentado em 2015, em vigor desde 2016 - passaram-se praticamente quatro anos, e as lacunas continuam. A implementação de programas de capacitação tecnológica não está em prática, embora esteja descrita no plano e devam favorecer a efetiva inclusão social e produtiva dessa população. Os estudantes desconhecem essas possíveis ações.

Percebemos aparentes soluções dentro da ordem capitalista, entre elas, a própria disponibilidade da modalidade. Porém, tais soluções ainda estão voltadas ao evidente controle social, pois as falas insatisfeitas dos participantes, quanto à empregabilidade, à insegurança pelo desemprego e às situações que essa população vivencia em seus contextos sociais, demonstram essa realidade. Alguns participantes tiveram coragem de dizer, em alto e bom tom, que estão "apenas (...) sobrevivendo no mundo".

Essa fala não pode ser ignorada, pois essas pessoas têm direitos iguais, embora ainda se encontrem em condições aquém do básico, garantido a todos, na Constituição Federal de 1988 (BRASIL, 1988). O reconhecimento da EJA, como modalidade da Educação Básica, descrito no PEE (2015-2025), é importante como formalização política pedagógica; porém, isto não tem aparecido no plano político concreto, ou melhor, nas práticas apontadas pelos participantes. Os resultados da nossa pesquisa apontam para o fato de que ainda não dispomos de políticas e diretrizes educacionais focadas em EJA, pois ainda necessitamos de ações governamentais pautadas em objetivos e critérios consolidados como políticas de Estado.

Interessante ressaltar que a Meta Brasil no PEE, projetada para 2015, era de 93,5\%. O Plano de Educação Estadual afirma: “erradicar o analfabetismo absoluto, até o final da década. Esta Meta pressupõe um esforço coletivo mais determinado dos que conduzem as políticas públicas da educação no Brasil e no Estado" (PARAÍBA/PEE, 2015, p. 59). 
A Meta 8, nesse plano, propõe elevar a escolaridade média da população de 18 a 29 anos, para, no mínimo, 12 anos de estudo, até o último ano de vigência do PEE, em 2025. A referida meta inclui as populações do campo, das regiões de menor escolaridade no estado e dos $25 \%$ mais pobres. A igualdade da escolaridade média entre negros e não negros, que se encontram declarados à FIBGE (Fundação Instituto Brasileiro de Geografia e Estatística), é outro objetivo do PEE (PARAÍBA, 2015).

Houve um "pontapé” favorável para a implantação de ações concretas na EJA; porém, ele ainda está no campo das ideias. Os resultados encontrados na análise documental apontam para situações promissoras no pensar a Educação de Jovens e Adultos, na Paraíba. Os fóruns de discussões e seminários promovidos pela Secretaria de Educação são a expressão dessas ações. Contudo, são pouquíssimas as cidades envolvidas nesses projetos, apenas algumas fazem-se presentes nos encontros do FEPAD-PB (Fórum Estadual Permanente de Apoio à Formação dos Profissionais do Magistério da Educação Básica da Paraíba), em prol da EJA, conforme consta no PEE (2015-2025), assim como nos encontros do projeto SER EJA, promovidos pela SEECT (Secretaria de Estado da Educação e da Ciência e Tecnologia). Dos 67 municípios existentes no Estado, apenas quatro têm presença declarada nos encontros, são eles: João Pessoa, Campina Grande, Bayeux e Santa Rita. Há alguma menção, também, a Guarabira e Areia. Portanto, os encontros contam com seis municípios participantes - número inferior aos $10 \%$ registrados para a representatividade estadual (PARAIBA, 2020).

Sendo assim, longe de possuir aspectos conclusivos e acabados, as informações encontradas nas falas dos participantes desta pesquisa - estudantes da EJA e trabalhadores da Paraíba - e, com base na análise documental, fica claro que os desafios são muitos para alcançarmos uma educação de qualidade e inclusiva em "todo" o estado da Paraíba.

Ações conjuntas em prol do público que depende da EJA para alcançarem uma formação básica de qualidade, o qual encontra-se à margem de inclusão na educação, têm agredido o direito adquirido à educação para todos, garantida por lei (BRASIL, 1996). Direitos adquiridos não estão sendo garantidos, na prática; exemplo disso é a ausência do lanche para os estudantes, que deveria ser gratuito e permanente, assim como a ausência do auxílio transporte e de materiais didáticos. Essas são evidências de práticas sociais aquém dos deveres básicos que deveriam ser garantidas pelas esferas de governança a esse público.

Apesar de os estudantes terem elogiado os professores, ainda há uma lacuna no processo de ensino-aprendizagem; os alunos dizem ter dificuldade com as ciências exatas, em geral. É fundamental contemplar as especificidades do público que chega cansado do 
trabalho, e precisa concentrar-se durante as aulas. Ações devem ser tomadas, no sentido de aproximar os assuntos das aulas às experiências trazidas pelos discentes, pois suas dificuldades evidenciam as falhas no campo didático adaptado para a modalidade em pauta.

A autonomia desse público deve consolidar-se por meio da Educação e de aspectos sociais. Ações governamentais precisam sair do papel, e abandonar a visão tradicional, cuja escola responde apenas aos anseios da sociedade, conforme abordado por Miranda (2008). Ainda, segundo o autor, o currículo adaptado ao público da Educação de Jovens e Adultos foca os princípios da produtividade no contexto capitalista. Porém, tal currículo deve agregar a práxis social, para que esses alunos usufruam de uma história de vida que demonstre os direitos e deveres alicerçados na independência, em poder construir "sua" própria história de vida, de acordo com o respeito e a autonomia garantidos pela Federação.

É complexa a tarefa dos governantes, representados pelas instituições de ensino, de atuar de forma concreta nas lacunas existentes na formação de trabalhadores estudantes da EJA, no estado da Paraíba. Os fragmentos de uma sociedade capitalista, classista, na qual a desigualdade insiste em aparecer, influenciam diretamente a prática social, que deveria estar mais forte na atualidade informatizada. A velocidade de propagação da informação e do conhecimento também chega fracionada, pois não tem força suficiente para acelerar assuntos que dizem respeito aos direitos de todos, que tratam da Educação para "todos", assim como do acesso básico de "todos" à subsistência (IMBERNÓN, 2016).

Esses fragmentos apareceram em toda pesquisa, nas entrelinhas da realidade expressa na voz dos participantes. Ao dizerem que escolheram a EJA pelo fator idade, pela necessidade em concluir o nível médio, por exigência do trabalho e para ingressar em formação técnica ou superior, os participantes estavam informando que, na verdade, não tiveram acesso básico aos direitos sociais.

Mencionaram que há incentivo governamental a EJA, dada sua oferta; porém, as lacunas geográficas persistem, pois o curso não está disponível em várias regiões do estado da Paraíba - afirmaram que a disponibilidade não é para todos. Além da pouca disponibilidade em nível estadual, não há benefícios como transporte ou lanche - previstos na legislação, e em conformidade com as necessidades básicas de cada cidadão (BRASIL, 1988).

Relataram a necessidade de começar a trabalhar cedo, para sustentar suas famílias; por isso, desistiram dos estudos em idade regular. Tal afirmação, novamente, evidencia a negligência de direitos expressos em lei, pois as dificuldades expostas nessas falas são 
gigantes e ecoa como um grito de socorro, de milhares de famílias na Paraíba, a quais vivem em condições precárias de subsistência.

A maioria dos participantes, mesmo afirmando que se sentem incluídos na sociedade, deixam claro que a desigualdade social existe, e que não existem incentivos governamentais palpáveis à disposição para os menos favorecidos. Há desigualdade de renda, falta de alimentação básica, falta de emprego.

Novamente, a falta dos benefícios expressos em lei, como direito de todos, volta à cena. Nossa pesquisa confirmou o descaso social evidenciado por estudantes/trabalhadores que vêm de longe, "a pé”, para estudar, sem se alimentar, por não terem recurso para tal. É evidente que a lei precisa ser praticada, fomentos para combater a desigualdade social - tão latente na Paraíba - devem ser incentivados.

Ao mencionarem as maiores dificuldades em sala de aula, o sono e o cansaço, dificultam seu aprendizado. Afirmam que nem todo o assunto abordado relaciona-se com suas práticas diárias ou aproximam-se delas. As várias comprovações registradas, aqui, ratificam o quanto é necessário desenvolver políticas públicas voltadas para a Educação de Jovens e Adultos. Além disso, a legislação deve ser, realmente, colocada em vigor, no sentido de construir uma sociedade mais justa e inclusiva, principalmente, para o público da Educação de Jovens e Adultos.

\section{Considerações finais}

A pesquisa confirmou a proposição levantada, pois, mesmo nas falas positivas e olhares conformistas de muitos, prevaleceram gritos de socorro em prol de uma sociedade mais justa, que ofereça condições básicas a todos, assim como acessos à educação para todos, conforme "direito" garantido por lei.

O que fazer para que as leis sejam cumpridas? Uma das possíveis respostas estaria no acesso à informação, pois os participantes afirmaram não conhecer seus direitos como alunos EJA. Segundo eles, nunca leram a respeito; confirmaram que o primeiro contato com essa informação aconteceu durante a apresentação da legislação sobre o tema. Encontros e desencontros sobre seus direitos tomaram forma em um mix de dilemas entre $\mathrm{O}$ "presente" e o "vivido" durante as explanações e discussões nos grupos focais desse estudo.

O resgate das experiências de vida trazidas pelos alunos - encontradas nas particularidades cotidianas de cada um -torna as aulas mais dinâmicas, desperta novos olhares, abre novas perspectivas, possibilita a interação e a integração dos conteúdos 
planejados. A busca pela escola, por esse público, satisfaz suas necessidades sociais particulares, suas expectativas quanto a novas oportunidades de trabalho e conquistas. Um novo pensar sobre a Educação de Jovens e Adultos é intrínseco a processos históricos individuais. Parece utópico, mas apesar de todos as condições de estudo que vivenciam a presente pesquisa identificou que os trabalhadores estudantes da EJA (núcleo UFPB), são pessoas que sonham com uma sociedade justa, com qualidade de vida e igualitária para todos e todas.

Ao estudar as Políticas Públicas direcionadas à EJA, e como elas influenciam o processo formativo de estudantes/trabalhadores, encontramos evidências que apontam para negligências governamentais quanto a direitos garantidos por lei. Tal diagnóstico vem da análise de documentos legais sobre a Educação Básica voltados à EJA, no Brasil, e no PEE Paraíba. Apesar de descrições interessantes, não podemos afirmar que existam práticas efetivas, conforme explicitado pelos estudantes participantes da pesquisa.

Os participantes não conheciam os programas de capacitação tecnológica para a população de jovens e adultos com baixo nível de escolarização formal e para os alunos com deficiência, na rede federal de educação profissional. Assim como a medida prevista na Lei $\mathrm{n}^{\circ}$ 11.947/2009, que especifica o direito à alimentação e ao transporte para estudantes da EJA tal direito não existe para eles, na prática.

A parceria com as áreas de saúde e assistência social busca acompanhar e monitorar o acesso à escola, em especial da população da EJA, bem como identificar os motivos do absenteísmo, do abandono e da evasão escolar, e colaborar com os municípios para garantir a frequência e o apoio ao aprendizado, de modo a estimular a ampliação do atendimento desses (as) estudantes, na rede pública regular de ensino - também não disponível para o público pesquisado.

Assim sendo, a pesquisa mostrou a complexa negação de ações governamentais, a qual fez-se presente nas entrelinhas das discussões realizadas. A intenção em realizar esse estudo foi incentivar discussões e questionamentos entre estudantes da EJA, o que ocorreu de forma satisfatória.

\section{REFERÊNCIAS}

BRASIL. Casa Civil. Constituição da República Federativa do Brasil de 1988. Brasília, 1988. 
BRASIL. Casa Civil. Lei no 11.947, de 16 de junho de 2009. Brasília, 2009. Disponível: http://www.planalto.gov.br/ccivil_03/_Ato2007-2010/2009/Lei/L11947.htm. Acesso em 02 jan. 2020.

BRASIL. Conselho de Saúde. Resolução no 466, de 12 de dezembro de 2012. Brasília, 2012.

BRASIL. Ministério da Educação. Lei de Diretrizes e Bases da Educação Nacional $\mathbf{n}^{\mathbf{0}}$ 9.394, de 20 de dezembro de 1996. Brasília, DF, MEC, 1996.

BRASIL. Ministério da Educação. Plano Nacional de Educação. Lei n ${ }^{\circ}$ 13.005/2014. Brasília, MEC, 2014.

BRASIL. Ministério da Educação. Programa Brasil Alfabetizado. Brasília, 15 de março de 2019. Disponível: http://portal.mec.gov.br/programa-brasil-alfabetizado. Acesso em 24 out. 2019.

CAMARGO, Poliana da Silva Almeida Santos; MARTINELLI, Selma de Cássia. Educação de adultos: percepções sobre o processo ensino-aprendizagem. Revista Semestral da Associação Brasileira de Psicologia Escolar e Educacional (ABRAPEE), São Paulo, n. 2, v. 10, p. 197-209, jul./dez. 2006.

DAS, Veenna; POOLE, Deborah. El estado y sus márgenes. Etnografías comparadas. Cuadernos de Antropología Social, Buenos Aires, n. 27, p. 19-52, 2008.

FLICK, Uwe. Introdução à pesquisa qualitativa. 3 ed. Porto Alegre: Artmed, 2009.

FREIRE, Paulo. A Educação na Cidade. São Paulo: Cortez, 1991.

FREIRE, Paulo. Conscientização. 3 ed. São Paulo: Moraes, 1980.

FREIRE, Paulo. Educação como prática de liberdade: a sociedade brasileira em transição. Rio de Janeiro: Paz e Terra, 2000.

GUI, Roque Tadeu. Utilização do Grupo Focal em Pesquisa Qualitativa Aplicada:

Intersubjetividade e Construção de Sentido. Psicologia (Florianópolis), Florianópolis, n. 1, v. 3, p. 135-159, 2003.

IMBERNÓN, Francisco. Qualidade de Ensino e Formação do Professorado. Cortez Editora, 2016.

INDICADOR DE ALFABETISMO FUNCIONAL. INAF Brasil 2018. Disponível: https://acaoeducativa.org.br/wp-content/uploads/2018/08/Inaf2018_Relat\%C3\%B3rioResultados-Preliminares_v08Ago2018.pdf. Acesso em 05 jan. 2020.

INSTITUTO BRASILEIRO DE GEOGRAFIA E ESTATÍSTICA. Censo 2010. Brasília, 2010. Disponível: https://censo2010.ibge.gov.br/. Acesso em 24 out. 2019.

INSTITUTO BRASILEIRO DE GEOGRAFIA E ESTATÍSTICA. Censo escolar da educação básica 2013 resumo técnico. Brasília, 2013. Disponível: 
http://portal.inep.gov.br/informacao-da-publicacao/-

lasset_publisher/6JYIsGMAMkW1/document/id/493780 Acesso em 24 out. 2019.

INSTITUTO BRASILEIRO DE GEOGRAFIA E ESTATÍSTICA. IBGE EDUCA. 2018. Disponível: https://educa.ibge.gov.br/jovens. Acesso em: 24 out. 2019.

INSTITUTO BRASILEIRO DE GEOGRAFIA E ESTATÍSTICA. Pesquisa nacional por amostras de domicílios. Censo 2018. Disponível:

https://biblioteca.ibge.gov.br/visualizacao/livros/liv94414.pdf. Acesso em 24 out. 2019.

KUENZER, Acácia Zeneida. Exclusão includente e inclusão excludente: a nova forma de dualidade estrutural que objetiva as novas relações entre educação e trabalho. In: SAVIANI, Demerval; SANFELICE, José Luís; LOMBARDI, José Claudinei (Org.). Capitalismo, trabalho e educação. 3 ed. Campinas: Autores Associados, 2005. p. 77-96.

LEFEVRE, Fernando; LEFEVRE, Ana Maria Cavalcanti; TEIXEIRA, Jorge Juarez Vieira. O discurso do sujeito coletivo: uma nova abordagem metodológica em pesquisa qualitativa. Caxias do Sul: EDUCS, 2000.

LÜDKE, Menga; ANDRÉ, Marli Eliza Dalmazo Afonso de. Pesquisa em educação: abordagens qualitativas. 9 ed. São Paulo: EPU, 2005.

MIRANDA, Joseval dos Reis. O currículo da formação inicial de professores que atuam na educação de jovens e adultos: do concebido ao vivido. Dissertação (Mestrado em Educação) - Universidade de Brasília, Brasília, 2008.

NAIFF, Luciene Alves Miguel; NAIFF, Denis Giovani Monteiro. Educação de Jovens e Adultos em uma análise psicossocial: representações e práticas sociais. Psicologia \& Sociedade. Florianópolis, n. 3, v. 20, p. 402-407, 2008.

PAIVA, Jane. Tramando concepções e sentidos para redizer o direito à educação de jovens e adultos. Universidade do Estado do Rio de Janeiro, Faculdade de Educação. Revista Brasileira de Educação, n. 33, v. 11, set./dez. 2006.

PAIVA, Vanilda Pereira. Educação popular e educação de adultos. São Paulo: Loyola, 1987.

PARAÍBA. Governo Estadual. Metodologia ser EJA cidadã matrículas da educação de jovens e adultos crescem 33\% . João Pessoa, 2019. Disponível:

https://paraiba.pb.gov.br/noticias/metodologia-ser-eja-cidada-matriculas-da-educacao-dejovens-e-adultos-crescem-33 Acesso em 14 jan. 2020.

PARAÍBA. Governo Estadual. Plano Estadual de Educação 2004-2014. João Pessoa, 2004. Disponível: http://www.gestaoescolar.diaadia.pr.gov.br/arquivos/File/pee/pee_pb.pdf . Acesso em 24 jan. 2020.

PARAÍBA. Governo Estadual. Plano Estadual de Educação 2015-2025. João Pessoa, 2015. Disponível: http://static.paraiba.pb.gov.br/2016/07/Lei-n\%C2\%BA-10.488-Plano-Estadualde-Educa\%C3\%A7\%C3\%A3o-ANEXO-DO-PLANO-ESTADUAL-1-3-1.pdf. Acesso em 24 out. 2019. 
PARAÍBA. Governo Estadual. Seminário estadual sobre educação de jovens e adultos

EJA e realizado em João Pessoa. 2019. Disponível:

https://paraiba.pb.gov.br/diretas/secretaria-da-educacao-e-da-ciencia-etecnologia/noticias/seminario-estadual-sobre-educacao-de-jovens-e-adultos-eja-e-realizadoem-joao-pessoa. Acesso em 14 jan. 2020.

SIQUEIRA, André Boccasius. O retorno de jovens e adultos aos estudos formais após 20, 30, 40 anos. Poiésis, Tubarão, n. 1, v. 2, p. 33-43, jan./jun. 2009.

SOARES, Leôncio. Educação de Jovens e adultos: diretrizes curriculares nacionais. Rio de Janeiro: DP\&A, 2002.

STRELHOW, Thyeles Borcate. Breve história sobre a educação de jovens e adultos no Brasil. Revista HISTEDBR On-line. Campinas, n. 38, p. 49-59, jun. 2010.

\section{SOBRE OS AUTORES:}

\section{Eloíde Teles Silva Grisi}

Possui Mestrado em Educação pela Universidade Federal da Paraíba (UFPB). É analista de qualidade acadêmica na Laureate Brasil. Pesquisadora no Grupo de Pesquisa em Avaliação da Educação Superior (GAES). E-mail: eloidegrisi @ gmail.com

iD http://orcid.org/0000-0002-3134-7344

\section{Maria das Graças Gonçalves Vieira Guerra}

Possui Pós-Doutorado pela Universidade do Porto - Portugal (FPCEUP), com Doutorado em Educação pela Universidade Federal da Paraíba (UFPB). É professora associada III da UFPB. É professora dos quadros permanentes dos Programas de Pós-Graduação em Educação (PPGE) e de Políticas Públicas, Gestão e Avaliação da Educação Superior (MPPGAV) da UFPB; Líder do Grupo de Pesquisa em Avaliação da Educação Superior- GAES-CNPq. Email: gracinhavieira@yahoo.com.br

iD http://orcid.org/0000-0002-6943-0338

\section{Joseval dos Reis Miranda}

Possui Doutorado em Educação pela Universidade de Brasília (UnB). É professor adjunto IV da UFPB. É professor dos quadros permanentes dos Programas de Pós-Graduação em Educação (PPGE) e do Mestrado Profissional em Letras-PROFLETRAS da UFPB; Líder do Grupo de Pesquisa em Gênero, Educação, Diversidade e Inclusão. E-mail: josevalmiranda@yahoo.com.br

(iD http://orcid.org/0000-0002-0713-0110 